\title{
Hypersensitivity to pituitary snuff with miliary shadowing in the lungs
}

\author{
W. E. MAHON, D. J. SCOT T ${ }^{1}, G$. ANSELL, \\ G. L. MANSON, AND R. FRASER

\begin{abstract}
From St. Nichoias Hospital, Plumstead, London; the Royal Postgraduate Medical School, London; and Whiston Hospital, Liverpool
\end{abstract}

Since 1924 powdered extracts of pig and ox pituitary glands have been used as nasal insufflations for the treatment of diabetes insipidus of mild to moderate severity, thereby avoiding the necessity for injections of pitressin tannate (Blumgart, 1922 ; Choay and Choay, 1924, 1928 ; Vidgoff, 1932 ; Smith, 1934). Choay and Choay (1946) and Marson (1955) have mentioned rhinorrhoea as the only side-effect of the powdered extracts. We wish to report a more serious complication in three patients who developed generalized miliary shadowing in the lung fields associated with bronchospasm and eosinophilia.

\section{CASE REPORTS}

CASE 1 S. B., a 27-year-old woman, presented in April 1961 with amenorrhoea and bitemporal hemianopia progressing to blindness, thirst, and polyuria. A craniotomy in September 1961 established the diagnosis of bilocular epidermoid cyst, arising from a Rathke's pouch remnant, pressing on the optic chiasma and hypothalamus. For her diabetes insipidus she received injections of pitressin tannate on alternate days. In December 1961 she began taking pitressin snuff two or three times daily with good result, and without trouble for the first two weeks.

She subsequently developed attacks of acute wheezing and dyspnoea lasting 20 to 30 minutes following each insufflation, and this side-effect became so distressing that she had to revert to injections. A chest radiograph at this time (Figs 1a and 1b) showed widespread miliary shadowing, whereas previous chest films had been normal.

Miliary tuberculosis was considered, but the absence of fever and negative sputum examinations made this unlikely. The Mantoux test was weakly positive. The blood count showed an eosinophilia of 1,040 cells/ mm. ${ }^{3}$ A skin test with the snuff was negative. In subsequent radiographs over the next eight weeks the miliary shadowing gradually subsided and disappeared (Fig. 1c), as did the eosinophilia. The course of events suggested a probable allergic basis for these changes despite the negative skin test. We now regard this patient as showing a transient reversible stage of the more permanent changes evident in cases 2 and 3 .

CASE 2 G. S. was 41 years old when she presented in 1950 with a three-month history of thirst and polyuria. She was passing up to 11 litres of urine in 24 hours. Investigations failed to reveal the cause of her diabetes insipidus. The menstrual periods were normal and visual fields full. Skull and chest radiographs were reported as normal. Syphilis, diabetes mellitus, and chronic renal disease were also excluded. Her symptoms were controlled with nasal insufflations of powdered posterior pituitary gland three to four times daily. She complained of rhinorrhoea and tightness of the chest during the first weeks of therapy, but these symptoms soon improved.

For the next nine years she continued on this therapy. In December 1959 she developed a cough which was slow to resolve. A chest radiograph showed extensive granular shadowing in the lung fields, affecting the upper and mid-zones predominantly. She improved up to a point, but was left with a chronic morning cough. In March 1960 the chest radiograph was unchanged. The Mantoux test with 10 units of O.T. was negative, but a blood count revealed a $5 \%$ eosinophilia with 450 eosinophils $/ \mathrm{mm}^{3}$

By March 1962 she had become breathless on the slightest exertion, and each insufflation of snuff was followed by bouts of coughing and wheezing. Crepitations were audible at both bases, but there was no cyanosis or finger-clubbing. An eosinophilia of $490 / \mathrm{mm}^{3}$ persisted. Therapy was changed to injections of pitressin tannate in oil on alternate days, and her respiratory symptoms have since improved, although she is still breathless on exertion. Sixteen months later the eosinophilia had decreased to $100 / \mathrm{mm}^{3}$, but the granular shadowing in the chest film showed no improvement. Immunological studies of the serum at this time showed the presence of precipitating antibodies against the heterologous serum proteins of porcine and bovine origins and also antibodies against pituitary antigens demonstrated by immunofluorescence tests. 


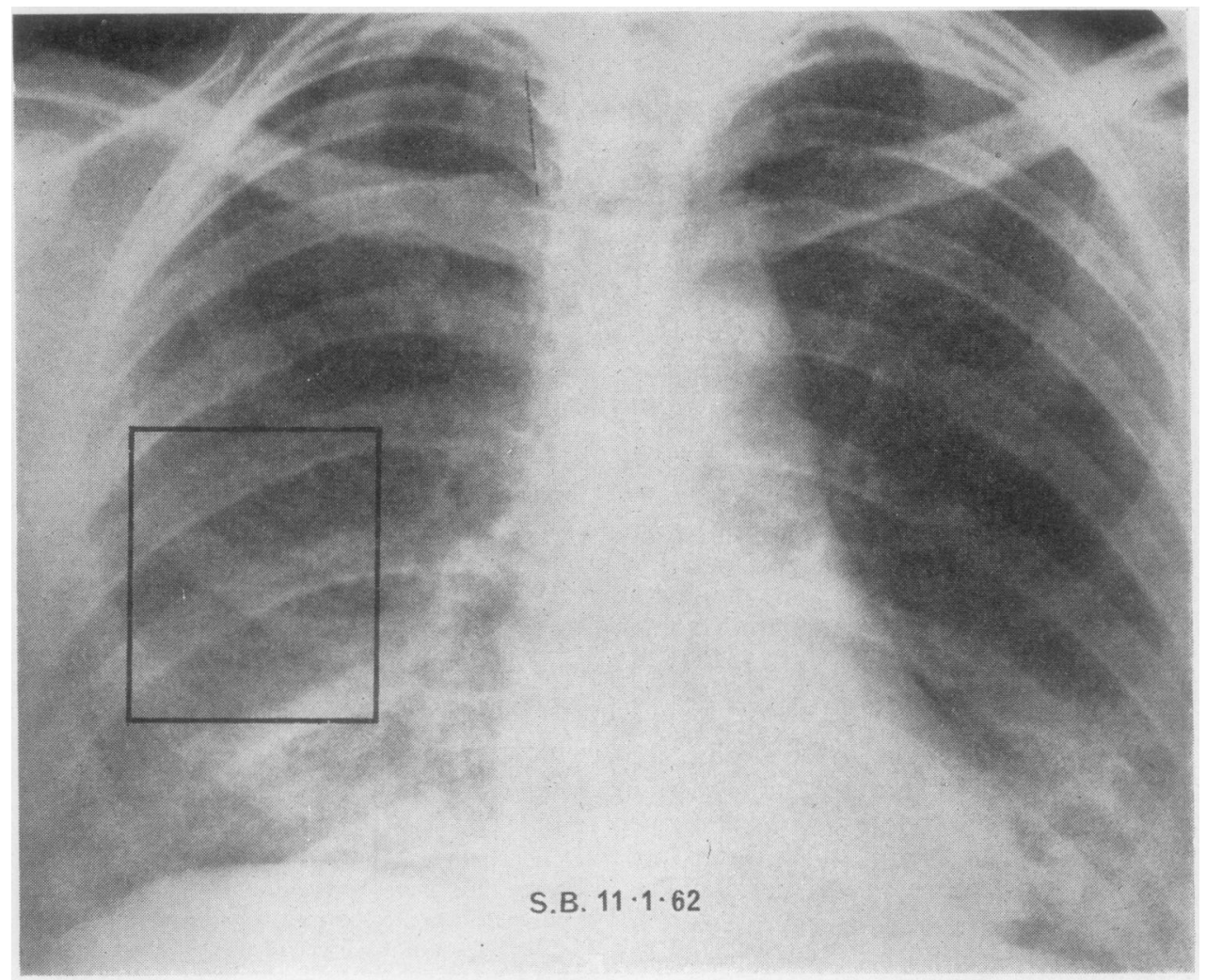

(a)

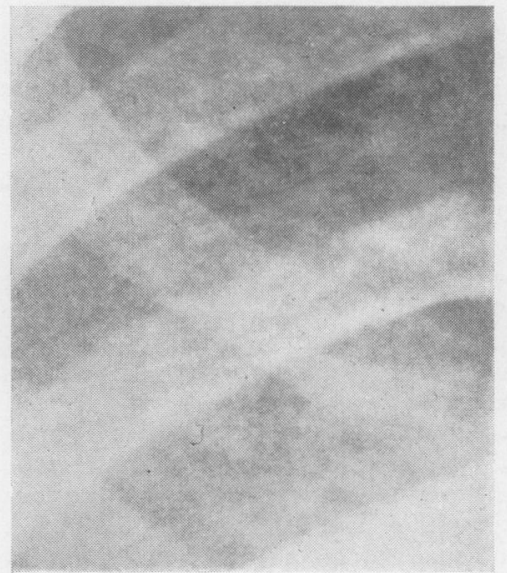

(b)

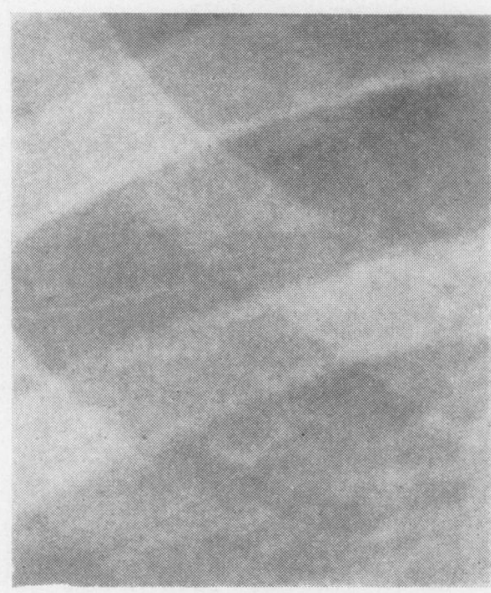

(c)

FIG. 1. Case 1. (a) Chest radiograph on 11 January 1962, showing widespread miliary shadowing; (b) detail of inset on (a)-note fine size of the constituent shadows; (c) same area as (b) taken on 25 April 1962, when the miliary shadowing had disappeared. 


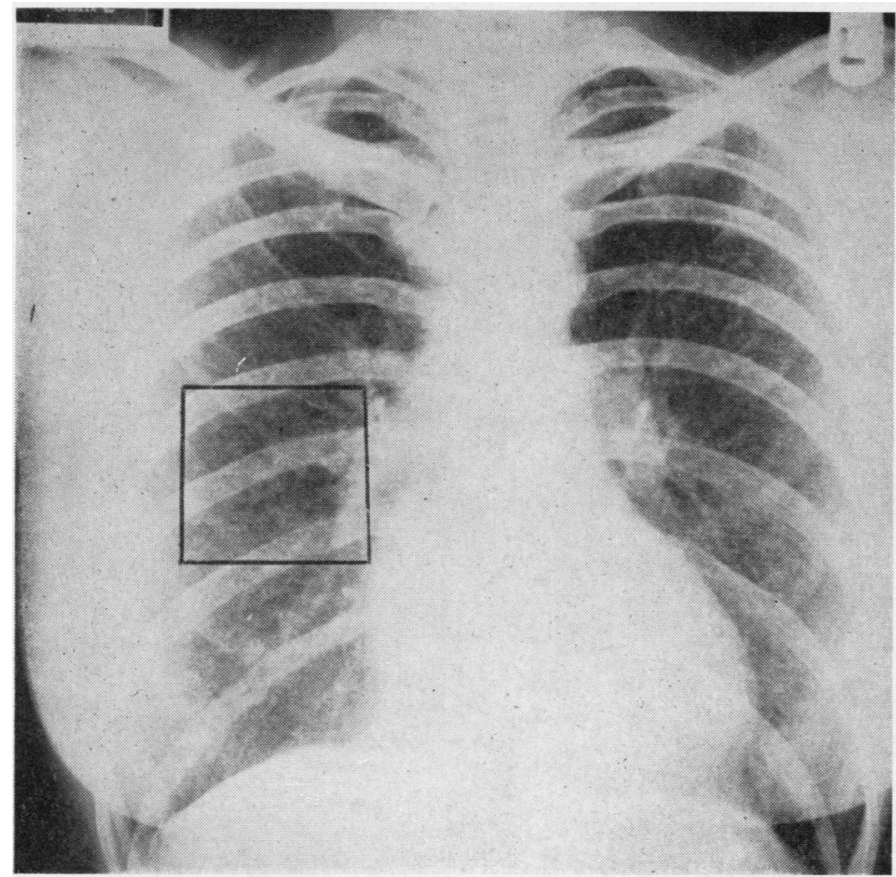

FIG. 2. Case 3. (a) Chest radiograph showing miliary shadowing; (b) deiail of inset.

(a)

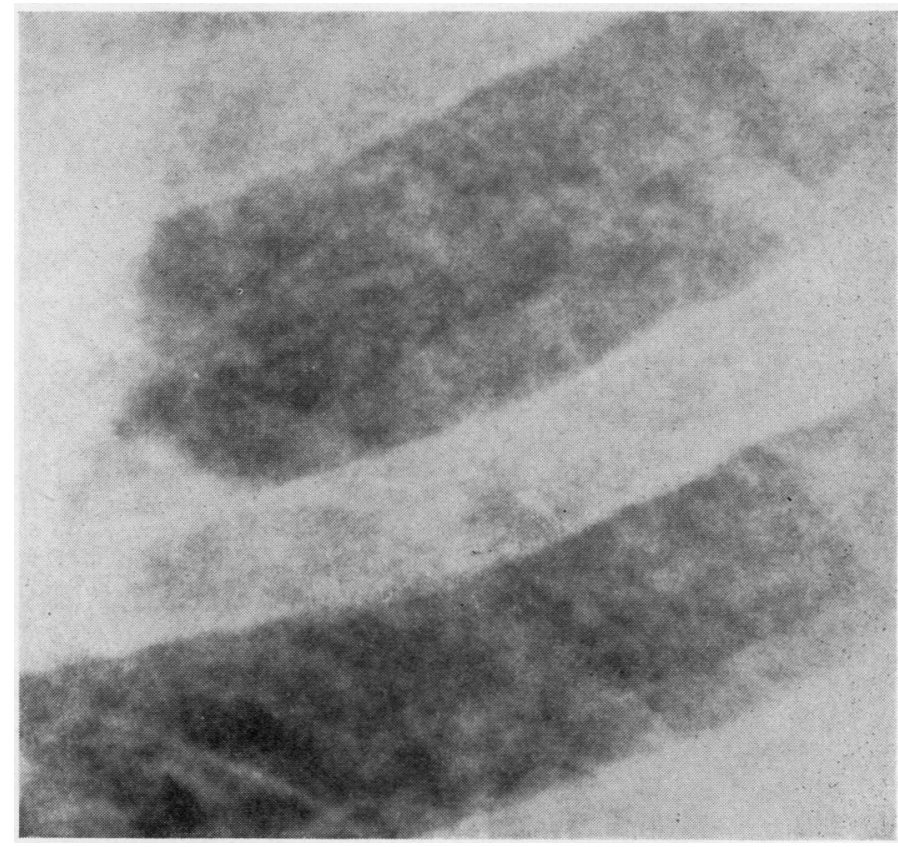

(b) 

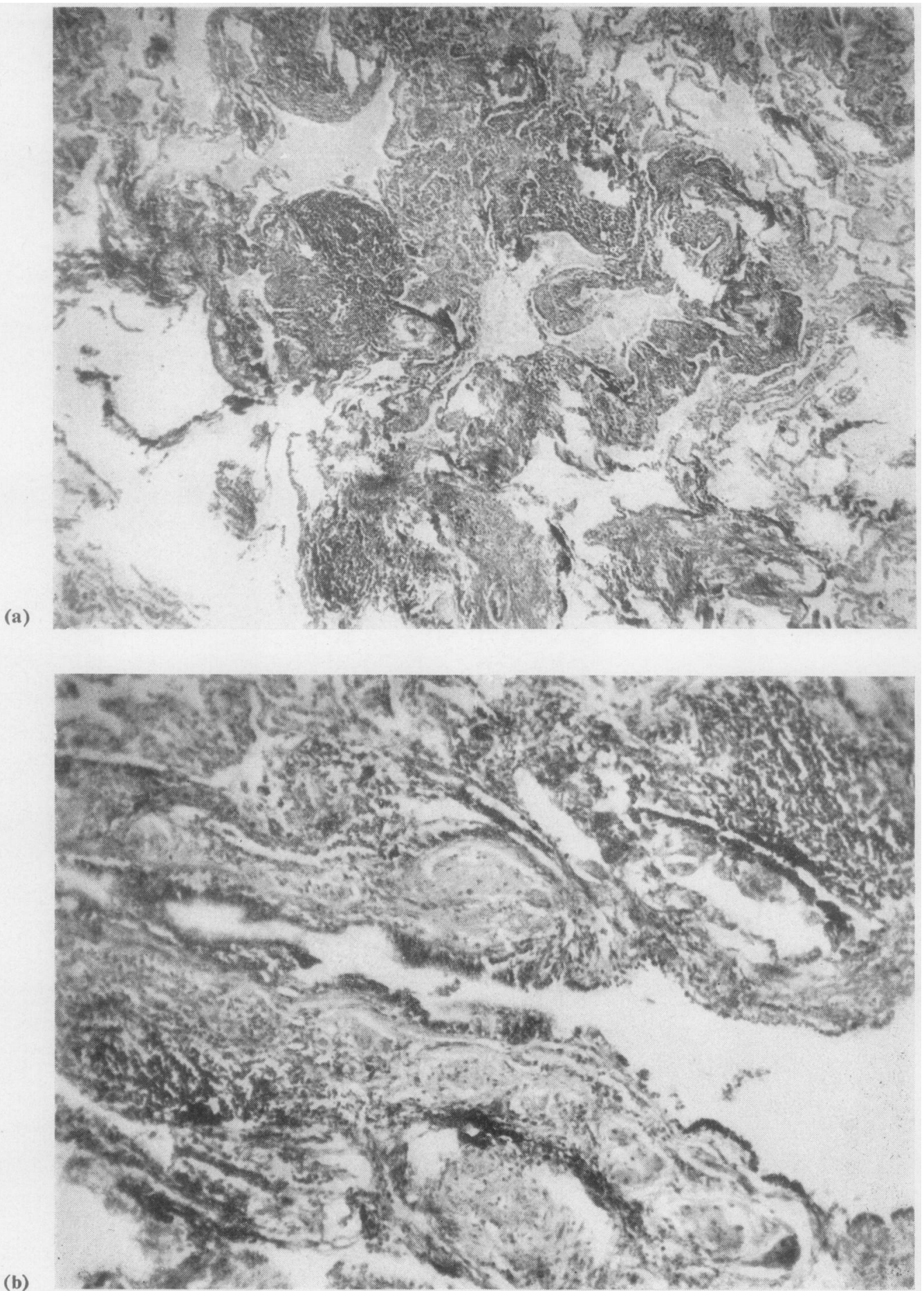

FIG. 3 


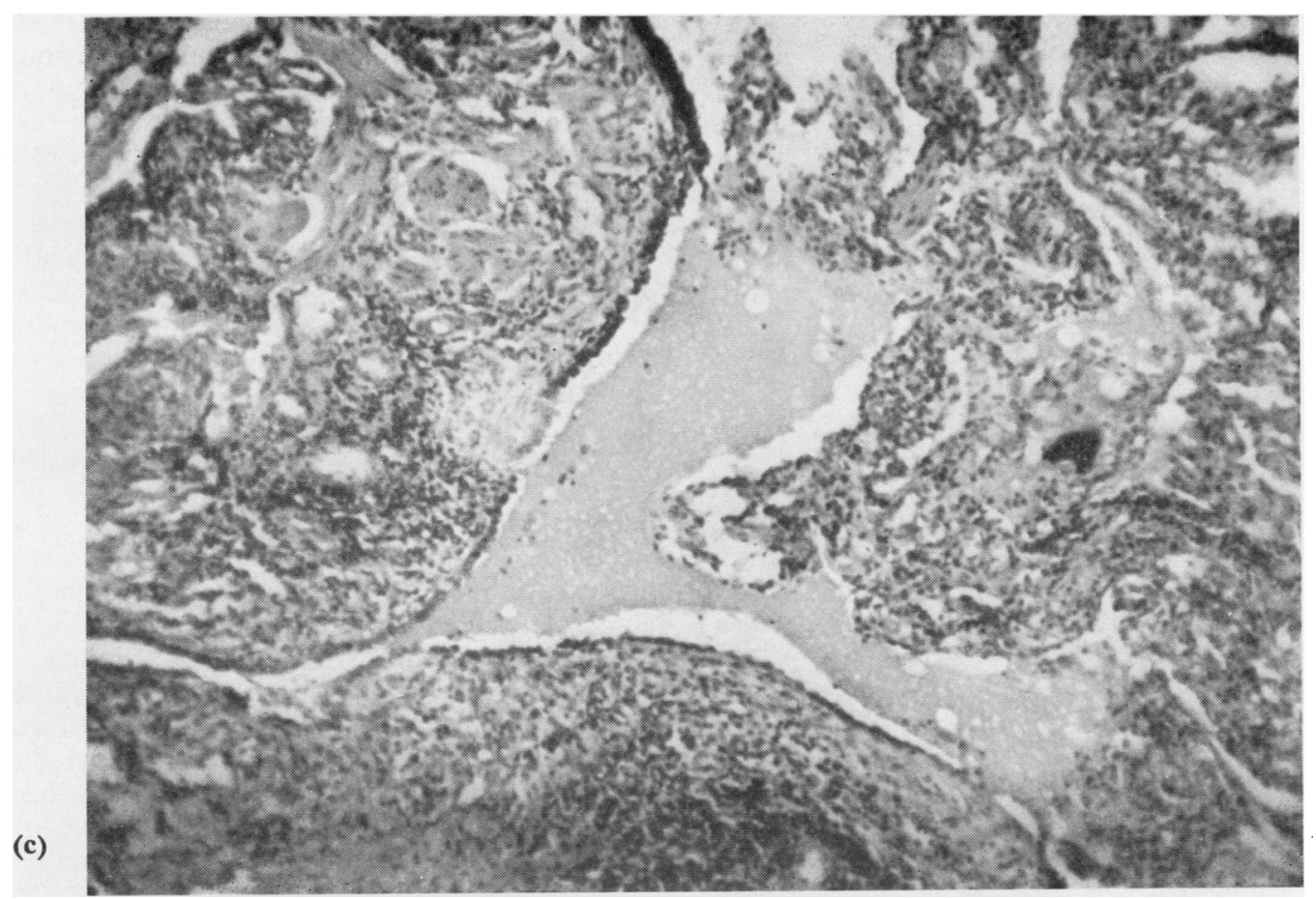

FIG. 3. Case 3. (a) Histology of lung biopsy $(\times 50)$, showing diffuse interstitial fibrosis with intra-alveolar oedema and desquamation. The cellular aggregations consist of lymphocytes and plasma cells; (b) lung biopsy $(\times 100)$ showing peri-bronchial fibrosis; $(c)$ lung biopsy $(\times 200)$ : cubical cell metaplasia and intra-alveolar oedema is shown.

CASE 3 Mrs. E. P. developed diabetes insipidus in 1958 at the age of 38 years. The cause was not established after full investigation. She was treated with pituitary snuff uneventfully until 1963, when she complained of paroxysmal attacks of wheezing. Slight eosinophilia $\left(280 / \mathrm{mm}^{3}\right)$ was present. The attacks were relieved by changing her snuff from fine-grain to a coarser grain variety. She still gets occasional wheezing, mild in degree.

The chest radiograph showed generalized fine mottling (Figs $2 a$ and $b$ ). Further extensive investigation, including Mantoux and Kveim tests, liver biopsy, and skeletal survey, were inconclusive, and a lung biopsy from the right lower lobe was therefore performed.

Histology Report There is diffuse, patchy, interstitial fibrosis of the lung with an intra-alveolar exudate of fibrinous oedema fluid and hyaline membrane formation (Fig. 3a). The fibrosis is maximal in the alveolar walls and ducts and extends into the respiratory bronchioles (Fig. 3b). The alveolar capillaries are increased in size and in number, and some have ruptured, producing alveolar haemorrhages. The alveoli themselves show cuboidal cell metaplasia with intra-alveolar desquamation (Fig. 3c). In some areas the alveolar spaces are completely obliterated and the capillaries destroyed.

A striking feature is the interstitial collections of lymphocytes and plasma cells, eosinophils being very scanty. The lymphocytic cells are present in large numbers and form focal aggregations.

The respiratory bronchi show fibrotic changes with marked muscle-coat hypertrophy. All vessels are thickened. No cyst formation is seen.

The histology is compatible with diffuse interstitial fibrosis from any cause (Scadding, 1960), with focalcell accumulations suggestive of an immune reaction.

Respiratory Function Tests (Table) Impaired gas transfer is shown by the low carbon monoxide transfer coefficient, but this is not severe enough to lower the oxygen saturation after prolonged exercise.

Similarly, the compliance is lowered and this is reflected in the vital capacity, but neither indicates more than moderate lung damage. Ventilation, as shown by $\mathrm{PaCO}_{2}$, is unimpaired. Although she no longer has any serious asthma, the forced expiratory tracing shows quite obvious airway obstruction.

Immunological Tests Skin prick and intracutaneous tests using porcine and bovine pituitary snuff extracts 
T A B L E

RESPIRATORY FUNCTION TESTS

\begin{tabular}{|c|c|c|c|}
\hline & At Rest & After Exercise & Normal Values \\
\hline \multirow[t]{4}{*}{$\begin{array}{l}\mathrm{PaCO}_{2} \\
\mathrm{SaO}_{2}\end{array}$} & $45 \mathrm{~mm} . \mathrm{Hg}$ & $41 \underset{95 \%}{\operatorname{mm}} . \mathrm{Hg}$ & $\begin{array}{c}36-44 \mathrm{~mm} \\
\mathbf{0}-97 \%\end{array}$ \\
\hline & \multicolumn{2}{|c|}{$\begin{array}{l}\text { Forced vital capacity } 2 \cdot 721 . \\
\text { Forced expiratory volume } 1.401 \text {. } \\
\text { Forced expiratory ratio } 52 \% \\
\text { Maximum expiratory flow rate } \\
1081 . \text { min. } \\
\text { Vital capacity } 2.761 .\end{array}$} & $\begin{array}{l}3.51 \text {. } \\
2.71 \text {. } \\
75 \% \\
4001 . / \mathrm{min} \\
3.51 .\end{array}$ \\
\hline & \multicolumn{2}{|c|}{ Compliance $0.0781 .1 \mathrm{~cm} . \mathrm{H}_{2} \mathrm{O}$} & $0 \cdot 151 . / \mathrm{cm} . \mathrm{H}_{2} \mathrm{O}$ \\
\hline & \multicolumn{2}{|c|}{$\begin{array}{l}\text { Carbon monoxide transfer } \\
\text { coefficient (single breath } \\
\text { method) } \\
13 \mathrm{ml} . / \mathrm{min} . / \mathrm{mm} \text {. Hg measured at } \\
\text { alveolar volume of } 4.31 \text {. }\end{array}$} & $25 \mathrm{ml} . \underset{\mathrm{Hg}}{\min } \mathrm{mm}$. \\
\hline
\end{tabular}

were positive, resulting in erythema, itching, and wealing. After the intracutaneous reaction there was a delayed oedematous response of marked degree, lasting 24 to 36 hours.

Provocative nasal insufflation of both porcine and bovine snuff produced rhinitis and asthma, with a watery nasal eosinophilic discharge. This reaction also occurred with insufflation of synthetic lysine vasopressin.

Serum precipitating antibodies were found against the porcine and bovine antigens in the pituitary snuff by gel diffusion test, immuno-electrophoresis, and immuno-fluorescent complement fixation techniques.

\section{DISCUSSION}

Pituitary snuff is commonly prepared by grinding a mixture of the dried posterior pituitary lobes of porcine and bovine pituitary glands down to a particle size of less than 50 microns, and diluting with an inert soluble powder, often lactose. When inhaled through the nose the major part of this powder is absorbed by the nasal mucosa, but some undetermined fraction is carried more distally; the smaller particles of this are known to pass to and through the smallest bronchioles to enter the alveoli.

An asthmatic reaction to this type of snuff is not uncommon. However, a coarser grained variety of snuff is also available and appears less liable to cause symptoms. This has a minimum particle diameter of between 180 and 250 microns (60 to 80 mesh U.S.P.). Processing to these specifications makes it considerably more expensive.

Pituitary snuff is largely used in the short-term treatment of nocturnal enuresis in children and does not, in this connexion, appear to cause pulmonary complications (Marson, 1955). Nevertheless, the transitory changes noted in case 1, after only a short period of treatment. indicate the necessity for caution. By contrast, patients with diabetes insipidus are necessarily treated for much longer periods, and this longer exposure to the fine-grain powder is sometimes associated with both asthmatic reactions and the development of precipitating antibodies to the porcine and bovine constituents of the snuff.

The discovery and study of these precipitating antibodies, with their implications, is the subject of a separate communication (Pepys, Jenkins, Lachman, and Mahon, 1965), in which cases 2 and 3 above are included. In a preliminary report to the Society for Endocrinology (Pepys et al., 1965), an interesting secondary finding was noted: patients using pituitary snuff could develop antibodies to human pituitary cells as well as to the snuff itself, a 'hetero-stimulated auto-reactive phenomenon'. It was thought that these antibodies definitely resulted from treatment and bore no relation to the cause of the diabetes insipidus.

In both cases 2 and 3 specific antibodies to the heterologous pituitary antigens of the snuff were found by a variety of techniques, including immuno-electrophoresis and fluorescent antibody tests, and in case 3 there was also a positive skin test. Immuno-serological examination was not performed in case 1.

The similarity to the lung reactions of farmer's lung (Pepys and Jenkins, 1965) and pigeon, budgerigar, and hen handler's lung (Hargreave, Pepys, Longbottom, and Wraith, 1966), with the comparable finding of specific precipitating antibodies, leads us to suggest that a similar immune reaction has been aetiologically responsible for the interstitial fibrosis in our patients.

The occurrence of asthma and the appearance of precipitins in the serum is probably much more common than pulmonary shadowing, though this latter may be of such fine texture as to escape discovery in miniature films. Transitory pulmonary 욱 shadowing, as exemplified by case 1 , might also have been missed in the absence of an early chest radiograph.

DIAGNOSIS Of particular relevance to this paper $N_{0}$ are other lesions causing diffuse interstitial pul- N monary fibrosis. Its occurrence has been mentioned 0 in occupational diseases associated with immune 0 reactions to exogenous antigens, such as asper- $\mathbb{D}$ gillosis, farmer's lung, and disorders of pigeon, $\stackrel{\infty}{+}$ hen, and budgerigar breeders. It occurs more $\underline{T}$ commonly in chronic idiopathic form, and as a $\stackrel{\vec{D}}{\circ}$ feature of such connective tissue diseases as $\stackrel{\mathbb{D}}{\mathscr{D}}$ rheumatoid arthritis, scleroderma, systemic lupus $\mathbb{\perp}$ erythematosus, and polyarteritis nodosa. In this context, it is not surprising that our case 3 had 
lung changes very similar histologically to those described by Mackay and Ritchie (1965) in patients with auto-immune disease and diffuse fibrosing alveolitis. The histological changes in our case 3 correlate well with the radiological appearances, which suggest lesions at the level of the alveolar ducts, and pulmonary function tests characteristic of changes in the gas exchanging part of the lung.

Lung mottling has been described in four cases of diabetes insipidus by Spillane (1952). However, the mottling was present at the onset of the disease, and none of the patients had been treated with snuff. The cause of the lung mottling was not established, but such mottling in association with diabetes insipidus has been described in eosinophilic granuloma, sarcoidosis, Hodgkin's disease, disseminated neoplasm, and miliary tuberculosis.

It is clearly most important to exclude miliary tuberculosis, which requires active and energetic treatment. If the patient is pyrexial, this may be far from easy in the early stages, particularly if the patient has received steroids (Ansell, 1958). The lung infiltrations of eosinophilic granuloma may precede diabetes insipidus by many years (Weiss and Johnson, 1957). However, the pulmonary shadowing is usually of a coarser reticular nature rather than the miliary type noted in our cases. There may be predominant upper lobe involvement, cyst and honeycomb formation, or pneumothorax. Focal bone lesions may also be present. In a comprehensive survey of the condition, Lewis (1964) quotes 75 patients in the literature with eosinophilic granuloma diagnosed by lung biopsy, and adds eight of his own ; 17 in all had diabetes insipidus. He noted that, when replacement fibrosis eventually occurs, there may be little or no evidence of eosinophilic or histiocytic infiltration.

Sarcoidosis is an occasional cause of diabetes insipidus. In the active stage, the association with adenopathy, skin, eye, and bone lesions, a negative tuberculin test, and a positive Kveim test suggest the diagnosis, which may then be confirmed by biopsy. Later, as in eosinophilic granuloma, only the scarring in the lungs may remain.

The pulmonary shadowing in our patients is almost certainly caused by an immune reaction to antigens present in the pituitary snuff. The immunological evidence for this is clearest in case 3 , and the histological findings showed an interstitial pulmonary fibrosis. In case 2 the radiological appearances also suggest pulmonary fibrosis. Although the injections of pitressin tannate might have been responsible for the antibodies noted in the serum, the symptoms produced by the inhala- tion of the snuff, and the improvement when this was abandoned, provide strong presumptive evidence of sensitivity. Similarly, in case 1 , the improvement in symptoms, eosinophilia, and pulmonary shadowing when the snuff was discontinued strongly suggest an allergic basis, possibly associated with transitory eosinophilic infiltrations in the lungs.

We think, therefore, that inhalations of posterior pituitary snuff may cause pulmonary fibrosis which may be irreversible. Snuff containing small particles appears to be most likely to cause this, and for long-term treatment a coarse-grain preparation with a minimum particle diameter of over 100 microns should be substituted. An alternative method of treatment by a synthetic lysine vasopressin nasal spray is now available, and this should minimize allergic complications (Fraser and Scott, 1963 ; Sjöberg and Luft, 1963 ; Spiegelman, 1963). However, it may be significant that one of our patients (case 3), who was tested against this substance, showed hypersensitivity phenomena.

It is most important that patients treated with posterior pituitary snuff should have initial control chest radiographs and periodic follow-up films so that the pulmonary changes may be detected at an early stage before irreversible fibrosis occurs. Serum precipitating antibody tests are also valuable in confirming the presence of sensitivity to pituitary snuff, which may precede the development of radiological changes.

\section{SUMMARY}

Three cases of miliary shadowing are described in patients with diabetes insipidus receiving posterior pituitary snuff inhalations.

In one patient the infiltrations were transitory. The other two patients had pulmonary fibrosis.

These changes are attributed to an immunological response to bovine and porcine antigens in the snuff.

\section{Prophylactic measures are discussed.}

We wish to acknowledge the helpful co-operation of Dr. A. J. Entwistle, the general practitioner of one of the patients. We should also like to thank Dr. Jack Pepys for the immunological tests, Dr. I. Williams for the histology of case 3, and Dr. Forgacs for helpful advice in the preparation of this paper.

\section{REFERENCES}

Ansell, G. (1958). Complications of adrenocortical therapy. A radiological survey. J. Fac. Radiol. (Lond.), 9, 113.

Blumgart, H. L. (1922). The antidiuretic effect of pituitary extract applied intranasally in a case of diabetes insipidus. Arch. intern. Med., 29, 508. 
Choay, A., and Choay, L. (1924). Traitement du diabète insipide par des inhalations d'extrait de lobe postérieur d'hypophyse. Rev. Neurol., 31 (1), 267.

_ (1928). Traitement du diabète insipide par des prises nasales de poudre de lobe postérieur d'hypophyse. Presse méd., 36, 1155.

(1946). Vingt ans de traitement du diabète insipide par prises nasales de poudre de lobe postérieur d'hypophyse. Ibid., 54, 500 .

Fraser, R., and Scott, D. J. (1963). Nasal spray of synthetic vasopressin for the treatment of diabetes insipidus. Lancet, 1, 1159.

Hargreave, F. E., Pepys, J., Longbottom, J. L., and Wraith, D. G. (1966). Bird breeder's (fancier's) lung. Ibid., 1, 445.

Lewis, J. G. (1964). Eosinophilic granuloma and its variants. Quart. J. Med., N.S., 33, 337.

Mackay, I. R., and Ritchie, B. (1965). Diffuse fibrosing alveolitis (diffuse interstitial fibrosis of the lungs): two cases with autoimmune features. Thorax, 20, 200.

Marson, F. G. W. (1955). Posterior pituitary snuff treatment of nocturnal enuresis. Brit. med. J., 1, 1194.
Pepys, J., and Jenkins, P. A. (1965). Precipitin (F.L.H.) test in farmer's lung. Thorax, 20, 21

- Lachman, P. J., and Mahon, W. E. (1965). An iatrogenic auto-antibody: Immunological responses to pituitary snuff in patients with diabetes insipidus. J. Endocr., 33, viii.

Scadding, J. G. (1960). Chronic diffuse interstitial fibrosis of the lungs. Brit.med. J., 1, 443.

Sjöberg, H., and Luft, R. (1963). Nasal spray of synthetic vasopressin for the treatment of diabetes insipidus. Lancet, 1, 1159.

Smith, F. M. (1934). Diabetes insipidus. Treatment by intranasal insufflation of posterior lobe pituitary powder. $J$. Amer. med. Ass., 102, 660 .

Spiegelman, A. R. (1963). Treatment of diabetes insipidus with synthetic vasopressin. Ibid., 184, 657 .

Spillane, J. D. (195). Four cases of diabetes insipidus and pulmonary disease. Thorax, 7, 134.

Vidgoff, B. (1932). Posterior pituitary therapy in diabetes insipidus. Endocrinology, 16, 289.

Weiss, W., and Johnson, D. G. (1957). Pulmonary histiocytosis X. Amer. Rev. Tuberc., 75, 319. 